\title{
Palmoplantar pustulosis: Factors causing and influencing the course of the disease
}

\author{
Magdalena Putra-Szczepaniak ${ }^{1, A, C, D}$, Joanna Maj ${ }^{1}, B, C, E$, Alina Jankowska-Konsur ${ }^{1, B, C, E}$, \\ Anna Czarnecka ${ }^{2,3, C, D}$, Anita Hryncewicz-Gwóźd́́l',A,C,D,F \\ ${ }^{1}$ Clinic of Dermatology, Venereology and Allergology, Wroclaw Medical University, Poland \\ 2 Regional Specialist Hospital, Research and Development Centre, Wrocław, Poland \\ ${ }^{3}$ Faculty of Physiotherapy, University School of Physical Education, Wrocław, Poland \\ A - research concept and design; $\mathrm{B}$ - collection and/or assembly of data; $\mathrm{C}$ - data analysis and interpretation; \\ $\mathrm{D}$ - writing the article; $\mathrm{E}$ - critical revision of the article; $\mathrm{F}$ - final approval of the article
}

Address for correspondence

Anita Hryncewicz-Gwóźdź

E-mail:anhryn@gmail.com

Funding sources

None declared

Conflict of interest

None declared

Received on August 2, 2018

Reviewed on August 22, 2018

Accepted on September 25, 2019

Published online on January 28, 2020

\begin{abstract}
Palmoplantar pustulosis (PPP) is a chronic inflammatory disease, most often occurring in middle-aged women. In the course of the condition, painful skin lesions appear on the hands and feet, i.e., areas that are extremely important in everyday life. Therefore, the disease significantly reduces quality of life. The pathogenesis of this disease is poorly understood, although it is known that genetic, immunological and environmental factors play a role in its development. Clinical observations confirm the role of nicotine and contact allergens in the development of the lesions. The skin lesions can also occur as a side effect of certain medications. In some cases, PPP coexists with other diseases, i.e., seronegative arthropathies, as well as celiac and thyroid diseases. There is also a connection between the disease and infectious bacterial foci. Exacerbation of the skin lesions is triggered by stress. Therefore, patients require multidirectional tests, since finding the cause of the disease is essential to administering effective treatment.
\end{abstract}

Key words: etiopathogenesis, palmoplantar pustulosis, exacerbating factors

Cite as

Putra-Szczepaniak M, Maj J, Jankowska-Konsur A, Czarnecka A,

Hryncewicz-Gwóźdź A. Palmoplantar pustulosis: Factors causing and influencing the course of the disease. Adv Clin Exp Med. 2020;29(1):157-163. doi:10.17219/acem/112613

DOI

10.17219/acem/112613

\section{Copyright}

Copyright by Author(s)

This is an article distributed under the terms of the

Creative Commons Attribution 3.0 Unported (CC BY 3.0)

(https://creativecommons.org/licenses/by/3.0/) 
Palmoplantar pustulosis (PPP) is a chronic inflammatory disease, the pathogenesis of which is poorly understood. It is classified either as a variant of psoriasis or as a separate entity. ${ }^{1}$ The distinct nature of PPP as opposed to psoriasis is indicated by an absence of psoriasis in the family, a late onset of the disease, a lack of typical psoriatic lesions, and increased incidence of contact allergy to metals. ${ }^{2,3}$ Palmoplantar pustulosis is more common in women than men, and most often occurs in middle age; it results in impairment of daily functioning and fulfilling social roles. Lesions are found on the palms and soles, usually symmetrically. ${ }^{1}$ Sterile pustules are formed on an erythematous base and subsequently dry within a few days. Desquamation and linear fissures can be observed. The disease becomes periodically exacerbated with eruptions of new pustules. Hyperkeratosis of the nails is frequently observed, and pustules may form beneath the nail plates (Fig. 1). ${ }^{1}$ Patients experience pain, itching or burning.

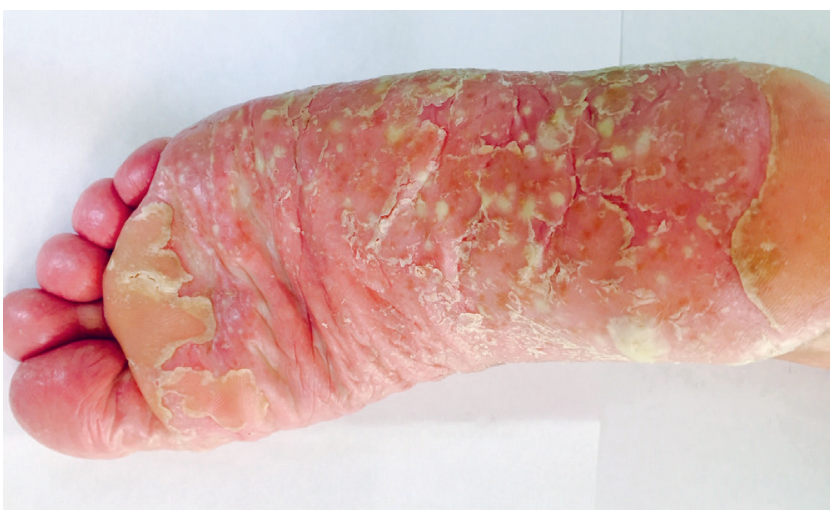

Fig. 1. Pustulosis localized on the sole

Lesions in the course of PPP develop in areas that are rich in eccrine sweat glands, which probably play a role in the pathogenesis of the disease. The results of recent research indicate that acrosyringium, the intraepidermal part of the excretory sweat gland ducts, is the main location where pustules form in the course of PPP. ${ }^{4}$

Biopsies of the skin lesions reveal changes similar to those seen in psoriasis: parakeratosis, a loss of the granular layer and spongiosis. Sterile pustules found in the upper layers of the epidermis are filled with neutrophils and eosinophils. Scattered, mixed infiltrations consisting of lymphocytes, neutrophils, eosinophils, and mast cells are found in the upper dermis and perivascularly. $\mathrm{T}$ lymphocytes predominate $\left(\mathrm{CD}^{+} \text {expression }\right)^{5,6}$

Contact dermatitis, pityriasis rubra pilaris, dyshidrotic eczema, and tinea should be taken into consideration in the differential diagnosis of PPP.

\section{Etiopathogenesis of palmoplantar pustulosis}

Genetic, immunological and environmental factors play a role in the development of PPP (Table 1). ${ }^{1}$
Table 1. Postulated pathogenic mechanisms in PPP development

\begin{tabular}{|c|c|}
\hline $\begin{array}{l}\text { Postulated pathogenic mechanisms } \\
\text { in PPP development }\end{array}$ & References \\
\hline \multicolumn{2}{|c|}{ Genetic background } \\
\hline $\begin{array}{l}\text { HLA-B27 antigen in } 32 \% \text { of patients } \\
\text { with PPP associated by joints pain } \\
\text { in the anterior thorax, hip or peripheral } \\
\text { joints }\end{array}$ & Szanto and Linse $(1991)^{9}$ \\
\hline $\begin{array}{l}\text { Gene ATG16L1 SNPs: rs2241880G and } \\
\text { rs2241879A }\end{array}$ & Douroudis et al. $(2011)^{10}$ \\
\hline Mutation of IL-36RN gene antagonist & Wang et al. (2016) $)^{11}$ \\
\hline \multicolumn{2}{|c|}{ Immunological background } \\
\hline $\begin{array}{l}\text { Increased blood levels: TNF-a, IL-17, } \\
\text { IL-22, and IFNY }\end{array}$ & Murakami et al. $(2011)^{14}$ \\
\hline $\begin{array}{l}\text { Increased blood level and expression } \\
\text { in skin lesions of IL-6 }\end{array}$ & Croxford et al. $(2014)^{16}$ \\
\hline $\begin{array}{l}\text { Increased expression of IL-17 in the PPP } \\
\text { lesions, without concomitant IL-12 and } \\
\text { IL-23 elevation }\end{array}$ & Bissonnette et al. $(2014)^{17}$ \\
\hline Dysregulation of IL-36 function & $\begin{array}{l}\text { Marrakchi et al. }(2011)^{30} \\
\text { Carrier et al. }(2011)^{32}\end{array}$ \\
\hline \multicolumn{2}{|c|}{ Environmental factors } \\
\hline $\begin{array}{l}\text { Cigarette smoking } \\
\text { - nicotine activates macrophages, } \\
\text { keratinocytes and lymphocytes } \\
\text { T as well as increases keratosis } \\
\text { of the excretory ducts } \\
\text { - PPP lesion regression after cessation } \\
\text { of smoking }\end{array}$ & $\begin{array}{l}\text { Hagforsen et al. }(2010)^{5} \\
\text { Elahmed }(2013)^{34}\end{array}$ \\
\hline $\begin{array}{l}\text { Contact allergy } \\
-25.2 \% \text { of patients with PPP positive } \\
\text { in patch test }\end{array}$ & Caca-Biljanovska et al. $(2005)^{35}$ \\
\hline $\begin{array}{l}\text { Drug side effect } \\
\text { - PPP observed as side effect of TNF } \\
\text { inhibitors }\end{array}$ & $\begin{array}{l}\text { Shmidt et al. }(2012)^{39} \\
\text { Collamer et al. }(2008)^{40}\end{array}$ \\
\hline $\begin{array}{l}\text { Focal bacterial infections } \\
\text { - tonsillectomy or effective treatment } \\
\text { of focal bacterial infections led } \\
\text { to significant improvement } \\
\text { or resolution of PPP }\end{array}$ & Takahara $(2011)^{44}$ \\
\hline $\begin{array}{l}\text { Chlamydia } \\
\text { - chlamydial antibody titer } \geq 1 / 16 \\
\text { in } 53 \% \text { of patients with PPP }\end{array}$ & Jansen et al. $(1980)^{46}$ \\
\hline
\end{tabular}

PPP - palmoplantar pustulosis; SNPs - single nucleotide polymorphisms; IL - interleukin; IFNY - interferon gamma; TNF - tumor necrosis factor.

\section{Genetic background}

The genetic background of PPP is not fully understood. Some authors consider PPP a variant of psoriasis, and studies comparing the prevalence of certain genes in these 2 diseases have been published. Genes coding for HLA-Cw6, WWCC HCR and CDSN5, located in the locus PSORS1 (6p21) on chromosome 6, are considered the main genetic basis of psoriasis. ${ }^{7}$ On the other hand, studies conducted on Swedish and British populations have shown that none of the abovementioned alleles are related to the occurrence of PPP. The frequency of occurrence of HLA-Cw6 is similar among patients with PPP (19-20\%) and healthy subjects 
(15\%). Similarly, WWCC HCR occurs in $50 \%$ of patients with PPP and $40 \%$ of healthy individuals. ${ }^{8,9}$

Another important genetic factor playing a role in the pathogenesis of psoriasis is the mutation of the ATG16L1 gene located on chromosome 2. ATG16L1 participates in the immunological response, and mutation of this gene leads to decreased production of antimicrobial peptides and enhanced production of pro-inflammatory cytokines interleukin 1 (IL-1) and IL-18, propagating systemic inflammation. More frequent occurrence of this mutation has been identified in inflammatory diseases such as psoriasis and Crohn's disease. More frequent occurrence of rs2241880 $\mathrm{G}$ and rs2241879A single nucleotide polymorphisms (SNPs) of the ATG16L1 gene has been observed among patients with PPP compared to healthy individuals. $^{10}$

Due to the possible coexistence of PPP with arthritis and arthralgia in some patients, the genetic base of PPP has been compared with that of psoriatic arthritis. A correlation was found between the HLA-B27 antigen, characteristic of psoriatic arthritis, and PPP. The HLA-B27 antigen was identified in $32 \%$ of patients with PPP associated with arthralgia in the area of the anterior thorax, hip or peripheral joints. ${ }^{9}$

Recent studies also indicate the role of antagonist receptor IL-36 (IL-36RN) gene mutation in the development of PPP, as well as in various forms of psoriasis: the plaque type, the generalized pustular type and the pustular palmoplantar type. ${ }^{11}$ This mutation is known to be the genetic basis of deficiency of IL-36 receptor antagonist (DITRA), a rare inherited autosomal recessive disorder characterized by disseminated pustular lesions resembling pustular psoriasis or acute generalized exanthematous pustulosis (AGEP). ${ }^{12}$

\section{Immunological background}

Immunological processes in the course of PPP lead to accumulation of large numbers of granulocytes in the area of the sweat gland excretion tract, the acrosyringium. ${ }^{5,13}$ Cytokines regulating immunological processes play a key role in the pathogenesis of the disorder. As in psoriasis, in PPP, increases in blood levels of pro-inflammatory interleukins such as tumor necrosis factor alpha (TNF- $\alpha$ ), IL-17, IL-22, and interferon gamma (IFN $\gamma$ ) are observed. ${ }^{14}$ However, psoriatic and PPP lesions have been found to be different. In psoriatic lesions, there are large amounts of cytokines produced by the Th17 lymphocytes (IL-12, IL-17 and IL-23), while a significant increase in the expression of IL-17 alone has been noted in PPP lesions, without concomitant IL-12 and IL-23 elevation. Therefore, isolated increases in IL-17 levels in PPP indicate that neutrophils, not Th-17 lymphocytes, are the main source of this response. ${ }^{15-17}$ A high level of IL-17 found locally in the epidermis stimulates keratinocytes to produce IL-6, which activates neutrophils and monocytes and exerts a chemotactic effect, attracting granulocytes to the epidermis, which leads to the formation of pustules. Interleukin 6 probably plays a crucial role in the formation of lesions in PPP, and increased levels of this cytokine have been found within the skin lesions as well as in the blood of patients with this disease. ${ }^{16}$ Interleukin 6 is a pro-inflammatory cytokine and belongs to the gp130 cytokine family. ${ }^{18,19}$ It activates receptor kinase JAK1/JAK2 and Tyk2, and regulates the STAT1/ STAT3 SHP2-MAPK signaling duct. ${ }^{19-21}$ Interleukin 6 stimulates synthesis of acute phase proteins, differentiation of B cells into mature plasma cells, differentiation and activation of T cells, and activation of Th17 lymphocytes and other non-immunological cells such as keratinocytes and fibroblasts. ${ }^{19,22,23}$ Moreover, IL-6 stimulates production of chemokines, e.g., IL-8 and monocyte chemotactic protein 1 (MCP-1), via macrophages and adhesion molecules in the vascular endothelium. This leads to increased migration of granulocytes and the formation of pustules..$^{23-25}$ Thus, IL- 6 may be an attractive new target in the treatment of PPP. ${ }^{20}$ Interleukin 36, produced by activated keratinocytes, is another cytokine that plays a role in the pathogenesis of psoriasis and PPP. This cytokine directly affects immune system cells and stimulates production of IL-1, IL-6, IL-23, TNF- $\alpha$, and IFN $\gamma,{ }^{26-28}$ which reciprocatively induces keratinocytes to produce IL-6, IL-8 and antibacterial peptides S 100 A7 and A15. Peptides S 100 A7 and A15, like other pro-inflammatory cytokines, enhance granulocyte migration. ${ }^{29-32}$ Recent genetics research indicates that IL-36 has a crucial role in the pathogenesis of PPP. As mentioned above, the IL-36RN gene mutation encoding the IL-36Ra protein, the antagonist of the IL-36 receptor, has been demonstrated in patients with localized and generalized forms of pustulosis, occurring in families and sporadically. As a result of this mutation, the function of IL-36 is dysregulated, resulting in increased production of IL-1, IL- 6 and IL-8, and the development of an inflammatory reaction. ${ }^{30,31,33}$

\section{Relationship between palmoplantar pustulosis and smoking}

Palmoplantar pustulosis is very common in smokers. There are many reports of lesion regression in patients with PPP after they quit smoking. ${ }^{34}$ Smoking causes oxidative stress and leads to an accumulation of inflammatory cells in the epidermis. Newly created free radicals stimulate cellular signaling ducts, as in psoriasis. Consequently, protein kinases are activated, which is also triggered by bacterial antigens. Moreover, nicotine triggers macrophages and keratinocytes to release cytokines, and activates $\mathrm{T}$ lymphocytes, which sustains the chronic inflammatory process. ${ }^{5,13}$ Recent studies indicate that acrosyringium plays a significant role in the development of PPP symptoms. The sweat glands are innervated by the cholinergic system, where acetylcholine (Ach) is the major inductor of sweating. Acetylcholine acts through 2 types of receptors: muscarinic (mAchR) and nicotinic (nAchR). The level of Ach 
is regulated by nicotinic Ach transferase, and can affect the functioning of the sweat glands. It has been shown that the level of Ach is lower in the lower layers of the acrosyringium, because the large quantities of esterase present there decompose the neurotransmitter. In the absence of Ach, nicotine binds to the $\mathrm{nAch}$ receptors. It is believed that nicotine Ach receptors, activated by nicotine and not Ach, may play a role in the pathogenesis of PPP and lead to the accumulation of neutrophils and eosinophils, and to the formation of pustules. Nicotine also affects keratinocytes around the sweat glands and causes increased keratosis of the excretory ducts. ${ }^{5,13}$

\section{Impact of contact allergens on skin lesions in palmoplantar pustulosis}

Based on clinical observations, contact hypersensitivity plays a role in the background of PPP. Clinical studies have shown that contact allergies to one or more substances occurred in $25.2 \%$ patients diagnosed with PPP, whereas in a control group comprising people diagnosed with psoriasis vulgaris, only in $11 \%$ of patients had contact allergies.

Significantly more women than men suffering from PPP presented positive patch tests. The following allergens were the most common: nickel, rubber additives, Peru balsam, chromium, mercury, and various fragrances. Therefore, performing patch tests in PPP patients who do not respond to treatment can be helpful in further medical care. In some centers, patch test are performed routinely in the course of diagnosing PPP, and avoidance of contact allergens is an important element of therapy. ${ }^{35,36}$

\section{Palmoplantar pustulosis as a side effect of drugs}

Palmoplantar pustulosis primarily affects adults and the elderly. Many patients with PPP are on long-term medication due to the coexistence of other chronic diseases, and skin lesions may appear as a side effect of these drugs. ${ }^{37}$ Hagforsen et al. documented that in a group of patients with PPP, $30 \%$ were treated with $\beta$-blockers, angiotensin-converting-enzyme (ACE) inhibitors or calcium channel blockers, $13 \%$ with anti-diabetic drugs, $30 \%$ with hormonal therapy, and $15 \%$ received antidepressants. ${ }^{38}$ Recently, widely used biological agents bring huge therapeutic benefits to many groups of patients. Although TNF inhibitors (adalimumab, infliximab and etanercept) have high efficacy in the treatment of psoriasis, their side effects include formation of psoriatic lesions. During TNF inhibitor therapy, exacerbation of psoriasis and the development of inverse, pustular and erythrodermic forms of the disease have been observed. ${ }^{39}$ Some reports consider palmoplantar pustular psoriasis the most common type of psoriasis induced by TNF inhibitors. ${ }^{39,40}$ The mechanism of the formation of psoriatic lesions as a side effect of TNF inhibitors is not fully understood. It has been suggested that blocking the crucial functions of pro-inflammatory cytokines, such as TNF, triggers alternative paths of $\mathrm{T}$ lymphocyte action that result in the occurrence of psoriatic lesions in predisposed patients. ${ }^{41}$

\section{Relationship between palmoplantar pustulosis and bacterial infections}

Clinical observations indicate an association between some inflammatory skin diseases and focal bacterial infections. ${ }^{42}$ Many case reports have described PPP associated with tonsillitis, chronic sinusitis or odontogenic infection. Tonsillectomy or effective treatment of focal bacterial infections led to significant improvement or resolution of PPP. ${ }^{43,44}$ In a group of 116 patients with PPP, 109 showed improvement after tonsillectomies. ${ }^{44}$ The association between PPP and tonsillitis has also been proved by the results of immunological and molecular tests. Increased expression of class II activation markers, such as CD25 and skin homing receptors (CLA and CCR6), on T cells in the palatine tonsils and in peripheral blood in patients with pustulosis has been observed. Moreover, there are ligands for these receptors, such as E-selectin and ligand 20, in psoriatic skin lesions. Excessive stimulation of T lymphocyte migration to the skin by bacteria colonizing the palatine tonsils probably plays a very important role in the pathogenesis of PPP as a focal disease. ${ }^{44}$ Furthermore, increased expression of the inducible co-stimulatory molecule (ICOS) receptor on tonsillar tissue $\mathrm{T}$ cells in patients with PPP also confirms the relationship between PPP and infectious foci. The ICOS receptor, like CD28, belongs to the co-stimulatory receptor family and is not present on resting lymphocytes. Its expression indicates stimulation of the immunological cells and plays a role in triggering $\mathrm{T}$ lymphocyte response..$^{42}$

Other microbiological factors than tonsillar and dental infections are also regarded as cause or aggravating factors in PPP. Erythematous-infiltrative skin lesions with eruptions resembling PPP are observed in some patients with Reiter's syndrome and classified as a spondyloarthropathy reactive arthritis. The classic triad of Reiter's syndrome symptoms consists of urethritis, arthritis and conjunctivitis. Some patients also suffer from dermal and mucosal lesions, such as balanitis circinata located on the penis glans, keratoderma blennorrhagicum located on the hands and feet, aphthous ulcers within the oral mucosa, and nail disorders. Skin lesions are mainly observed coexisting with Chlamydia trachomatis (Ch. trachomatis) infections. ${ }^{45}$ It has been postulated that $C h$. trachomatis infections may be a potential cause of isolated pustulosis. This theory is supported by the observation of high antibody titers (equal to or higher than 1/64) against Chlamydia more frequently in patients with PPP (38\%) than in psoriatic patients (13\%), patients with eczema or urticaria (12\%) and a control group of healthy individuals (3\%). Chlamydia antibody titers greater than or equal to $1 / 16$ were observed in $53 \%$ of patients with PPP. ${ }^{46}$

Anecdotal case reports also indicate Helicobacter pylori as a causative agent in PPP. ${ }^{47}$ 


\section{Stress as a possible factor aggravating the course of palmoplantar pustulosis}

Psychological factors, particularly stress, can play a significant role in the pathogenesis of certain dermatological diseases, including PPP. About $90 \%$ of patients with PPP report exacerbations of the disease in association with stress. Psychological tests have confirmed these clinical observations. A study based on the Eysenck Personality Questionnaire (EPQ), which measures 3 personality factors (extraversion-introversion, neuroticism and psychoticism), showed that fear, anxiety and psychosomatic disorders occur in $43 \%$ of patients with PPP, compared to $19 \%$ of people in the control group. ${ }^{48}$ Patients with PPP have also been subjected to the Inventory of Situations and Responses to Anxiety (ISRA). Fear and activation of the autonomic nervous system, manifested by tachycardia, dry mouth and sweating, was observed in $85 \%$ of patients with PPP, compared to $19 \%$ in the control group. ${ }^{48}$

\section{Relationship between palmoplantar pustulosis and gluten intolerance}

It is suspected that gluten intolerance might play a role in the pathogenesis of PPP, but the results of published studies are inconclusive. In a population of Swedish patients with PPP, the presence of IgA anti-gliadin antibodies was demonstrated in $18 \%$ and of anti-transglutaminase tissue in $7-10 \%$ of the subjects who did not report gastrointestinal symptoms. However, the duodenal mucosa biopsy in a group of patients with anti-gliadin antibodies demonstrated intestinal villi atrophy. In most patients, adherence to a gluten-free diet resulted in regression of the skin lesions. ${ }^{38,49}$ Different results were obtained in patients from Germany; neither anti-gliadin antibodies nor anti-transglutaminase tissue were detected in patients with PPP. The discrepancies may be related to many factors, such as ethnic differences between the populations surveyed. ${ }^{50}$

\section{Coexistence of palmoplantar pustulosis with other diseases}

\section{Seronegative arthropathies coexisting with palmoplantar pustulosis}

Palmoplantar pustulosis is one of the symptoms of a group of syndromes classified as seronegative spondyloarthropathies. These disorders include synovitis/acne/ pustulosis/hyperostosis/osteitis (SAPHO) syndrome, Sonozaki syndrome and Reiter's syndrome.

The SAPHO syndrome was described in 1987 as the coexistence of synovitis, acne, PPP, hyperostosis, and osteitis. ${ }^{51}$ Skin lesions can precede, occur simultaneously with or follow osteoarticular symptoms. The timespan between lesion formation and osteoarticular symptoms does not exceed 2 years. ${ }^{52}$ The etiopathogenesis of SAPHO syndrome is unknown. The adverse effect of retinoids among patients treated for severe acne was considered as a possible cause, but this theory was not confirmed, since a significant number of patients with SAPHO syndrome had not been treated with retinoids. ${ }^{53}$ Infectious agents have also been suspected as part of the etiology of SAPHO syndrome. In some patients, Corynebacterium has been isolated from the sternoclavicular joints. However, the role of this pathogen is questionable. ${ }^{53,54}$

Pustulotic arthro-osteitis (PAO) was first described by Sonozaki in 1979 as symmetrical erythematous and pustular lesions on the hands and feet accompanied by sternoclavicular joint pain. Recently, it has been suggested that Sonozaki syndrome should be classified as a spectrum of SAPHO syndrome. However, SAPHO syndrome and other spondylopathies, like psoriatic arthritis and Reiter's syndrome, are related to the HLA B27 antigen, while in Sonozaki syndrome, the prevalence of this antigen is low. ${ }^{53}$

\section{Thyroid diseases in patients with palmoplantar pustulosis}

Thyroid diseases have been observed more frequently in women with PPP than in a healthy population. Thyroid dysfunction coexists in $25 \%$ of studied women suffering from PPP. These disorders include hypothyroidism, hyperthyroidism, struma nodosa, and any thyroid surgery. Due to the fact that PPP coexists with thyroid diseases, it is advisable to gather more data concerning PPP patients and conduct screening of their thyroid functions. ${ }^{55}$

\section{Summary}

Palmoplantar pustulosis is a chronic skin disease resistant to treatment. It causes significant impairment of the patients' functioning and adversely affects social interactions. Since the pathogenesis of PPP involves genetic, immunological and environmental factors, patient examinations should be omnidirectional. The key to diagnosis is to collect a detailed medical history, especially concerning comorbidities, medications, exacerbating factors, smoking, and intensity of response to stress in everyday life. The coexistence of bacterial infections as factors provoking eruptions or exacerbations of pustular skin lesions should be excluded. It is advisable to conduct patch tests in order to detect contact allergy. It seems that in the future, modern molecular techniques could be helpful in detecting family predisposition to PPP. Determining the cause of the disease is extremely important for the effective treatment of patients with PPP. 


\section{ORCID iDs}

Magdalena Putra-Szczepaniak (1) https://orcid.org/0000-0001-6340-7164 Joanna Maj (1) https://orcid.org/0000-0001-8300-8208 Alina Jankowska-Konsur (10) https://orcid.org/0000-0003-4944-5388 Anna Czarnecka (1) http://orcid.org/0000-0002-6621-9537 Anita Hryncewicz-Gwóźdź (i) https://orcid.org/0000-0002-1601-471X

\section{References}

1. Yamamoto T. Extra-palmoplantar lesions associated with palmoplantar pustulosis. J Eur Acad Dermatol Venereol. 2009;23(11):1227-1232.

2. Ammoury A, El Sayed F, Dhaybi R, Bazex J. Palmoplantar pustulosis should not be considered as a variant of psoriasis. J Eur Acad Dermatol Venereol. 2008;22(3):392-393.

3. de Waal AC, van de Kerkhof PC. Pustulosis palmoplantaris is a disease distinct from psoriasis. J Dermatolog Treat. 2011;22(2):102-105.

4. Murakami M, Ohtake T, Horibe $\mathrm{Y}$, et al. Acrosyringium is the main site of the vesicle/pustule formation in palmoplantar pustulosis. J Invest Dermatol. 2010;130(8):2010-2016.

5. Hagforsen E, Michaëlsson G, Stridsberg M. Normal and PPP-affected palmoplantar sweat gland express neuroendocrine markers chromogranins and synaptophysin differently. Arch Dermatol Res. 2010; 302(9):685-693.

6. Eriksson MO, Hagforsen E, Lundin IP, Michaëlsson G. Palmoplantar pustulosis: A clinical and immunohistological study. Br J Dermatol. 1998;138(3):390-398.

7. Allen $\mathrm{MH}$, Ameen $\mathrm{H}$, Veal $\mathrm{C}$, et al. The major psoriasis susceptibility locus PSORS1 is not a risk factor for late-onset psoriasis. J Invest Dermatol. 2005;124(1):103-106.

8. Asumalahti K, Ameen M, Suomela S, et al. Genetic analysis of PSORS1 distinguishes guttate psoriasis and palmoplantar pustulosis. J Invest Dermatol. 2003;120(4):627-632.

9. Szanto E, Linse U. Arthropathy associated with palmoplantar pustuIosis. Clin Rheumatol. 1991;10(2):130-135.

10. Douroudis K, Kingo K, Traks T, et al. ATG16L1 gene polymorphisms are associated with palmoplantar pustulosis. Hum Immunol. 2011;72(7): 613-615.

11. Wang TS, Chiu HY, Hong JB, Chan CC, Lin SJ, Tsai TF. Correlation of IL36RN mutation with different clinical features of pustular psoriasis in Chinese patients. Arch Dermatol Res. 2016;308(1):55-63.

12. Nakai N, Sugiura K, Akiyama M, Katoh N. Acute generalized exanthematous pustulosis caused by dihydrocodeine phosphate in a patient with psoriasis vulgaris and a heterozygous IL36RN mutation. JAMA Dermatol. 2015;151(3):311-315.

13. Hagforsen E, Hedstrand H, Nyberg F, Michaëlsson G. Novel findings of Langerhans cells and interleukin-17 expression in relation to the acrosyringium and pustule in palmoplantar pustulosis. Br J Dermatol. 2010;163(3):572-579.

14. Murakami M, Hagforsen $E$, Morhenn V, Ishida-Yamamoto A, lizuka H. Patients with palmoplantar pustulosis have increased IL-17 and IL-22 levels both in the lesion and serum. Exp Dermatol. 2011;20(10):845-847.

15. Kagami S, Rizzo HL, Lee JJ, Koguchi Y, Blauvelt A. Circulating Th17, Th22, and Th1 cells are increased in psoriasis. J Invest Dermatol. 2010; 130(5):1373-1383.

16. Croxford AL, Karbach S, Kurschus FC, et al. IL-6 regulates neutrophil microabscess formation in IL-17A-driven psoriasiform lesions. J Invest Dermatol. 2014;134(3):728-735.

17. Bissonnette R, Nigen S, Langley RG, et al. Increased expression of IL$17 \mathrm{~A}$ and limited involvement of IL-23 in patients with palmoplantar (PP) pustular psoriasis or PP pustulosis: Results from a randomised controlled trial. J Eur Acad Dermatol Venereol. 2014:28(10):1298-1305.

18. NeurathMF, FinottoS.IL-6 signaling in autoimmunity, chronicinflammation and inflammation-associated cancer. Cytokine Growth Factor Rev. 2011:22(2):83-89.

19. Rincon M. Interleukin-6: From an inflammatory marker to a target for inflammatory diseases. Trends Immunol. 2012;33(11):571-577.

20. Jones SA, Scheller J, Rose-John S. Therapeutic strategies for the clinical blockade of IL-6/gp130 signaling. J Clin Invest. 2011;121(9):3375-3383.

21. Miyoshi K, Takaishi M, Nakajima K, et al. Stat3 as a therapeutic target for the treatment of psoriasis: A clinical feasibility study with STA-21, a Stat3 inhibitor. J Invest Dermatol. 2011;131(1):108-117.
22. Ataie-Kachoie P, Pourgholami MH, Morris DL. Inhibition of the IL-6 signaling pathway: A strategy to combat chronic inflammatory diseases and cancer. Cytokine Growth Factor Rev. 2013;24(2):163-173.

23. Ishihara K, Hirano T. IL- 6 in autoimmune disease and chronic inflammatory proliferative disease. Cytokine Growth Factor Rev. 2002;13(4-5): 357-368.

24. Romano M, Sironi M, Toniatti, et al. Role of IL- 6 and its soluble receptor in induction of chemokines and leukocyte recruitment. Immunity. 1997;6(3):315-325.

25. Bartoccioni E, Scuderi F, Marino M, Provenzano C. IL-6, monocyte infiltration and parenchymal cells. Trends Immunol. 2003;24(6): 299-300.

26. Blumberg H, Dinh H, Dean C Jr, et al. IL-1RL2 and its ligands contribute to the cytokine network in psoriasis. J Immunol. 2010;185(7): 4354-4362.

27. Tortola L, Rosenwald E, Abel B, et al. Psoriasiform dermatitis is driven by IL-36-mediated DC-keratinocyte crosstalk. J Clin Invest. 2012; 122(11):3965-3976.

28. Johnston $A$, Xing $X$, Guzman AM, et al. IL-1F5, -F6, -F8, and -F9: A novel IL-1 family signaling system that is active in psoriasis and promotes keratinocyte antimicrobial peptide expression. J Immunol. 2011;186(4):2613-2622.

29. Skov L, Beurskens FJ, Zachariae CO, et al. IL-8 as antibody therapeutic target in inflammatory diseases: Reduction of clinical activity in palmoplantar pustulosis. J Immunol. 2008;181(1):669-679.

30. Marrakchi S, Guigue P, Renshaw BR, et al. Interleukin-36-receptor antagonist deficiency and generalized pustular psoriasis. $N$ Engl J Med. 2011;365(7):620-628.

31. Tripodi D, Conti F, Rosati et al. IL-36 a new member of the IL-1 family cytokines. J Biol Regul Homeost Agents. 2012;26(1):7-14.

32. Carrier Y, Ma HL, Ramon HE, et al. Inter-regulation of Th17 cytokines and the IL-36 cytokines in vitro and in vivo: Implications in psoriasis pathogenesis. J Invest Dermatol. 2011;131(12):2428-2437.

33. Capon F. IL36RN mutations in generalized pustular psoriasis: Just the tip of the iceberg? J Invest Dermatol. 2013;133(11):2503-2504.

34. Elahmed HH. Rapid improvement of palmoplantar psoriasis after cessation of smoking. Sultan Qaboos Univ Med J. 2013;13(1):188-189.

35. Caca-Biljanovska N, V'Ickova-Laskoska M, Balabanova-Stefanova M, Grivceva-Panovska V. Frequency of delayed-type hypersensitivity to contact allergens in palmoplantar psoriasis. Prilozi. 2005;26(2): 131-141.

36. Ito T, Mori T, Fujiyama T, Tokura Y. Dramatic exacerbation of palmoplantar pustulosis following strongly positive nickel patch testing. Int J Dermatol. 2014;53(5):e327-e329.

37. Bordel-Gómez MT, Sánchez-Estella J, Martínez-González O, Cardeñoso-Alvarez ME. Palmoplantar psoriasis: A paradoxical adverse reaction induced by adalimumab. J Eur Acad Dermatol Venereol. 2009; 23(4):444-445.

38. Hagforsen $\mathrm{E}$, Michaëlsson $\mathrm{K}$, Lundgren $\mathrm{E}$, et al. Women with palmoplantar pustulosis have disturbed calcium homeostasis and a high prevalence of diabetes mellitus and psychiatric disorders: A casecontrol study. Acta Derm Venereol. 2005;85(3):225-232.

39. Shmidt E, Wetter DA, Ferguson SB, Pittelkow MR. Psoriasis and palmoplantar pustulosis associated with tumor necrosis factor-a inhibitors: The Mayo Clinic experience, 1998 to 2010. J Am Acad Dermatol. 2012;67(5):e179-e185.

40. Collamer AN, Guerrero KT, Henning JS, Battafarano DF. Psoriatic skin lesions induced by tumor necrosis factor antagonist therapy: A literature review and potential mechanisms of action. Arthritis Rheum. 2008;59(7):996-1001.

41. Bordel-Gómez MT, Sánchez-Estella J, Martínez-González O, Cardeñoso-Alvarez ME. Palmoplantar psoriasis: A paradoxical adverse reaction induced by adalimumab. J Eur Acad Dermatol Venereol. 2009; 23(4):444-445

42. Kobayashi S. Tonsil-related skin diseases and possible involvement of T cell co-stimulation in chronic focal infection. Adv Otorhinolaryngol. 2011;72:83-85.

43. Tsuboi H, Katsuoka K. Pustulosis palmaris et plantaris with prominent hyperkeratosis of the soles. J Dermatol. 2006;33(12):892-895.

44. Takahara M. Clinical outcome of tonsillectomy for palmoplantar pustulosis and etiological relationship between palmoplantar pustulosis and tonsils. Adv Otorhinolaryngol. 2011;72:86-88. 
45. Quint KD, van der Helm-van Mil AH, Bergman W, Lavrijsen AP. Mucocutaneous abnormalities in Chlamydia trachomatis-induced reactive arthritis [in Dutch]. Ned Tijdschr Geneeskd. 2010;154:A1614

46. Jansen CT, Hollmén, Pajarre R, Terho P. Antichlamydial antibodies in chronic palmoplantar pustulosis. Acta Derm Venereol. 1980;60(3): 263-266.

47. Martin Hübner A, Tenbaum SP. Complete remission of palmoplantar psoriasis through Helicobacter pylori eradication: A case report. Clin Exp Dermatol. 2008;33(3):339-340.

48. Sáez-Rodríguez M, Noda-Cabrera A, Alvarez-Tejera S, et al. The role of psychological factors in palmoplantar pustulosis. J Eur Acad Dermatol Venereol. 2002;16(4):325-327.

49. Michaëlsson G, Kristjánsson G, Pihl Lundin I, Hagforsen E. Palmoplantar pustulosis and gluten sensitivity: A study of serum antibodies against gliadin and tissue transglutaminase, the duodenal mucosa and effects of gluten-free diet. Br J Dermatol. 2007;156(4):659-666.

50. Weisenseel P, Kuznetsov AV, Ruzicka T, Prinz JC. Palmoplantar pustulosis is not inevitably associated with antigliadin antibodies. $\mathrm{Br} J \mathrm{Der}$ matol. 2007;156(6):1399-1400.
51. Károlyi Z, Harhai I, Erós N. Dermatologic aspects of SAPHO-syndrome. Orv Hetil. 2001;142(33):1801-1804.

52. Chamot AM, Benhamou CL, Kahn MF, Beraneck L, Kaplan G, Prost A. Acne-pustulosis-hyperostosis-osteitis syndrome: Results of a national survey (85 cases). Rev Rhum Mal Osteoartic. 1987;54(3):187-196.

53. Stanford CW, Kollipara R, Melookaran AM, Hall JC. Palmoplantar pustular psoriasis following initiation of a beta-blocker: Disease control with low-dose methotrexate. Cutis. 2014;94(3):153-155.

54. Matzaroglou Ch, Velissaris D, Karageorgos A, Marangos M, Panagiotopoulos E, Karanikolas M. SAPHO Syndrome diagnosis and treatment: Report of five cases and review of the literature. Open OrthopJ. 2009;3:100-106.

55. Giménez-García R, Sánchez-Ramón S, Cuellar-Olmedo LA. Palmoplantar pustulosis: A clinicoepidemiological study. The relationship between tobacco use and thyroid function. J Eur Acad Dermatol Venereol. 2003;17(3):276-279. 